\title{
Vitamin E-Mediated Modulation of Glutamate Receptor Expression in an Oxidative Stress Model of Neural Cells Derived from Embryonic Stem Cell Cultures
}

\author{
Afifah Abd Jalil, ${ }^{1,2}$ Huzwah Khaza'ai, ${ }^{1}$ Norshariza Nordin, ${ }^{1,2}$ \\ Nur'izzati Mansor, ${ }^{1,2}$ and Amirah Salwani Zaulkffali ${ }^{3}$ \\ ${ }^{1}$ Department of Biomedical Science, Faculty of Medicine and Health Science, Universiti Putra Malaysia, \\ 43400 Serdang, Selangor, Malaysia \\ ${ }^{2}$ Genetics and Regenerative Medicine Research Centre, Faculty of Medicine and Health Science, Universiti Putra Malaysia, \\ 43400 Serdang, Selangor, Malaysia \\ ${ }^{3}$ Department of Nutrition and Dietetics, Faculty of Medicine and Health Science, Universiti Putra Malaysia, \\ 43400 Serdang, Selangor, Malaysia \\ Correspondence should be addressed to Huzwah Khaza’ai; huzwah@gmail.com
}

Received 6 July 2017; Revised 5 October 2017; Accepted 29 October 2017; Published 20 November 2017

Academic Editor: Indumathi Somasundaram

Copyright (C) 2017 Afifah Abd Jalil et al. This is an open access article distributed under the Creative Commons Attribution License, which permits unrestricted use, distribution, and reproduction in any medium, provided the original work is properly cited.

\begin{abstract}
Glutamate is the primary excitatory neurotransmitter in the central nervous system. Excessive concentrations of glutamate in the brain can be excitotoxic and cause oxidative stress, which is associated with Alzheimer's disease. In the present study, the effects of vitamin $\mathrm{E}$ in the form of tocotrienol-rich fraction (TRF) and alpha-tocopherol ( $\alpha$-TCP) in modulating the glutamate receptor and neuron injury markers in an in vitro model of oxidative stress in neural-derived embryonic stem (ES) cell cultures were elucidated. A transgenic mouse ES cell line (46C) was differentiated into a neural lineage in vitro via induction with retinoic acid. These cells were then subjected to oxidative stress with a significantly high concentration of glutamate. Measurement of reactive oxygen species (ROS) was performed after inducing glutamate excitotoxicity, and recovery from this toxicity in response to vitamin E was determined. The gene expression levels of glutamate receptors and neuron-specific enolase were elucidated using real-time PCR. The results reveal that neural cells derived from $46 \mathrm{C}$ cells and subjected to oxidative stress exhibit downregulation of NMDA, kainate receptor, and NSE after posttreatment with different concentrations of TRF and $\alpha$-TCP, a sign of neurorecovery. Treatment of either TRF or $\alpha$-TCP reduced the levels of ROS in neural cells subjected to glutamate-induced oxidative stress; these results indicated that vitamin $\mathrm{E}$ is a potent antioxidant.
\end{abstract}

\section{Introduction}

Vitamin E is a fat-soluble compound with antioxidant properties that naturally exists in eight forms (alpha-, beta-, gamma, and delta-tocopherol and alpha-, beta-, gamma-, and deltatocotrienol); each isomer possesses unique biological properties [1]. The difference between tocopherol and tocotrienol is the number and position of methyl groups attached to the aromatic ring [2]. In short, tocopherols are saturated forms of vitamin $\mathrm{E}$, whereas tocotrienols possess an isoprenoid side chain. The latter variant of vitamin $\mathrm{E}$ only occurs at very low levels in nature, with the highest concentration found in palm oil. Currently, there is increased interest in the tocotrienolrich fraction (TRF) of palm oil. TRF consists of $25 \%$ alphatocopherol $(\alpha-\mathrm{TCP})$ and $75 \%$ tocotrienol. TRF from palm oil has been reported to possess potent antioxidant, anticancer, and cholesterol-lowering activities $[2,3]$.

At normal concentrations, glutamate functions as a major neurotransmitter in the brain that is critical for cognition, memory, and learning. However, elevated levels of glutamate can cause overstimulation of glutamate receptors, which can excessively excite nerve cells and results in the generation of ROS that can damage cells. Furthermore, glutamate overstimulation was associated with neurodegenerative diseases 
such as Alzheimer's disease (AD) and Parkinson's disease (PD) [4]. Overstimulation of glutamate receptors such as NMDA, AMPA, and kainate receptors can cause an influx of calcium ions into the postsynaptic membrane. High levels of ATP are required to produce the energy needed to restore the intracellular calcium ion concentrations to normal. This high energy requirement will cause mitochondria to generate more reactive oxygen species (ROS) as a natural byproduct. ROS is a chemically reactive species containing oxygen and includes peroxides, superoxides, hydroxyl radicals, and singlet oxygen [5]. Generally, these molecules are a byproduct of DNA, amino acid, and lipid oxidation that significantly damage cells. Oxidative stress is the condition whereby ROS production is greater than the capacity of the body to reduce oxidation.

This study aims to elucidate the protective role of vitamin E against glutamate toxicity and to understand how vitamin $\mathrm{E}$ is involved in modulating glutamate receptor function, antioxidant activity, and neuron-specific enolase (NSE) expression as an injury marker to achieve neurorecovery in an oxidative stress model in vitro. Establishment of a transgenic mouse embryonic stem (ES) cell line (46C) provided a method with a renewable source of cells that can generate both neurons and glial cells in vitro. This cell line was engineered to express Sox-1/eGFP, which is a marker for neural precursor cells and facilitates its differentiation into a neural lineage in an in vitro system. In this present study, we mimic oxidative stress in the brain using glutamate excitotoxicity in neural cells derived from the $46 \mathrm{C}$ cell line using 4-/4+ protocol as previously described; this protocol successfully generated neural cells in vitro to produce a mixed culture of neuronal cells and glial cells [6-8]. It is predicted that both forms of vitamin E (TRF and $\alpha$-TCP) would exert a neuroprotective effect against oxidative stress in neural cultures.

\section{Materials and Methods}

2.1. Culture Conditions of Undifferentiated 46C Cells. The transgenic mouse ES cell line (46C) was obtained from Dr. John Orr Mason at the University of Edinburgh, UK. The 46C cells were cultured and passaged regularly on tissue culture flasks coated with a $0.1 \%$ gelatine solution. The $46 \mathrm{C}$ cell line was cultured in embryonic stem cell medium (ESM), which comprised $1 \%$ MEM nonessential amino acids, $1 \mathrm{mM}$ sodium pyruvate, $0.1 \mathrm{mM} 2$-mercaptoethanol, and $2 \mathrm{mM} \mathrm{L}$-glutamine into 1X Glasgow's MEM (GMEM, Gibco). Complete GMEM media were then aliquoted and supplemented with $15 \%$ foetal bovine serum (Gibco) and 10-20 ng/ml human recombinant leukaemic inhibitory factor (LIF) (Merck).

2.2. Induction of Differentiation. $46 \mathrm{C}$ cells were differentiated using 4-/4+ protocols as described by Bain et al., 1995. The $46 \mathrm{C}$ cell line was subjected to an 8-day induction procedure which consisted of 4 days of culture as aggregates in the absence of retinoic acid (RA) and 4 days of culture in the presence of RA. To establish the inductions, a confluent culture of undifferentiated $46 \mathrm{C}$ cells was dissociated with $0.25 \%$ trypsin, and the cell suspension was counted using a haemocytometer. Approximately $5 \times 10^{6}$ cells [9] were seeded in a $100 \mathrm{~mm}$ bacteriological grade Petri dish (nontissue culture) in $10 \mathrm{~mL}$ of medium (standard medium as mentioned above) without LIF. Cell suspensions were cultured as multicellular aggregates known as embryoid bodies (EBs) for 2 days. The medium was changed, and the cultures were maintained for an additional 2 days. On day 4 of the EBs culture, the medium was changed with the addition of all-trans-retinoic acid (Sigma). After another 2 days, the medium was replaced with fresh medium containing RA, and the expression of enhanced green fluorescent protein (eGFP) was assessed under an inverted fluorescence microscope (OLYMPUS IX51) to identify neural progenitor cells (NPCs). After an 8-day induction period, the EB suspension was dissociated with a high concentration of trypsin (4X Trypsin-EDTA, 4\% chicken serum in IX PBS) for 5 minutes in a $37^{\circ} \mathrm{C}$ water bath and agitated to obtain a single-cell suspension, which was then counted using a haemocytometer prior to plating on adhesive substratum dishes precoated with $2 \mu \mathrm{g} / \mathrm{ml}$ laminin from Engelbreth-Holm-Swarm murine sarcoma basement membrane (Sigma) and $10 \mu \mathrm{g} / \mathrm{mL}$ of polyD-lysine hydrobromide (PDL, Sigma) in IX PBS. The 24-well plate was coated first with PDL for at least 20 minutes at room temperature, after which the flask was washed with IX PBS twice before laminin was added and incubated at least 20 minutes at room temperature. Excess laminin was suctioned out before the cells were plated. The cells were seeded at a density of approximately $1-2 \times 10^{5} / \mathrm{cm}^{2}$ for terminal differentiation in serum-free medium comprising a $1: 1$ ratio of DMEM/F12/N2 supplement (Gibco) and Neurobasal/B27 supplement (Gibco). The medium was replaced with fresh N2/B27 complete medium every two days.

2.3. Immunocytochemistry (ICC). The primary antibodies used targeted class III $\beta$-tubulin (Sigma, T2200) and glial fibrillary acidic protein (GFAP; Abcam, AB10062). Class III $\beta$-tubulin is a microtubule component that is normally expressed in neuronal cells, and GFAP is expressed in multiple cells in the central nervous system (CNS), including astrocytes and glial cells. On day 6 after neural postplating, the attached neuron-like cells in the 24 well plates were gently washed 3 times with $1 \mathrm{X}$ PBS prior to being fixed with $4 \%$ paraformaldehyde. The cells were then permeabilized in $1 \%$ Triton-X100; blocked with a solution comprising $0.3 \%$ BSA, $10 \%$ goat serum, and 10\% Tween-20 in 1X PBS; and treated with primary antibody. The cells were then incubated with goat anti-rabbit IgG- 488 secondary antibodies (Abcam: 150077) for class III $\beta$-tubulin and goat anti-mouse IgG488 secondary antibodies (Abcam: 150113) for GFAP, after which the cells were counterstained with $10 \mu \mathrm{g} / \mathrm{mL}$ DAPI (Invitrogen) to detect nuclei. The cells were stored in 1X PBS and kept in the dark until the specimens could be viewed under a fluorescence microscope.

2.4. Glutamate Dose Response and Time Course Study. On day 6 after plating the neural cells, the cells in the 24well plates were challenged with six different concentrations $(0,31.25,62.5,125,250$, and $500 \mathrm{mM})$ of L-glutamic acid monosodium salt hydrate (Sigma) diluted in $\mathrm{XX}$ PBS to 
calculate the $\mathrm{IC}_{50}$ of glutamate toxicity in the cell cultures. The day before glutamate was added, the old medium was replaced with DMEM/F12 and Neurobasal medium $(1: 1$ ratio) in the absence of $\mathrm{N} 2$ and $\mathrm{B} 27$ supplements; this new medium was designated minimal medium. Then, glutamate was administered to the cells and incubated for 24 hours at $37^{\circ} \mathrm{C}$ in an atmosphere containing $5 \% \mathrm{CO}_{2}$ and $95 \%$ humidity. A similar volume of $1 \mathrm{X}$ PBS was added to the cells as a negative control. After 24 hours, $100 \mu \mathrm{L}$ of MTT $(2 \mathrm{mg} / \mathrm{ml})$ was added to each well and incubated with the cells for 4 hours at $37^{\circ} \mathrm{C}$ in an atmosphere containing $5 \%$ $\mathrm{CO}_{2}$. Then, $200 \mu \mathrm{L}$ of DMSO was added to each well to dissolve the formazan crystals. The cells were incubated for an additional 5 minutes in the dark at room temperature and gently agitated for $10-15$ seconds, and $100 \mu \mathrm{L}$ from each well was transferred into a 96-well plate. The absorbance value was measured using an enzyme-linked immunosorbent assay (ELISA) reader (BioTek ELx800, USA) at the $570 / 630 \mathrm{~nm}$ wavelength. The graph of the cell viability against dose and time course was plotted. The $\mathrm{IC}_{50}$ and $\mathrm{IC}_{20}$ were calculated, and the $\mathrm{IC}_{20}$ was used throughout the entire study.

A time course study was conducted on day 6 after neural plating; cells in 24-well plates were challenged with the $\mathrm{IC}_{20}$ calculated from the dose response study for 5 different time intervals $(0,4,8,12$, and 24 hours). After the culture medium was replaced with fresh minimal medium, the calculated $\mathrm{IC}_{20}$ of glutamate was added to each well in the plate and incubated for the abovementioned intervals at $37^{\circ} \mathrm{C}$ in an atmosphere containing $5 \% \mathrm{CO}_{2}$ and $95 \%$ humidity. The cells were then subjected to the MTT protocol as described above.

2.5. Posttreatment with Vitamin $E$ on Glutamate-Induced Neural Cells. $\alpha$-tocopherol and TRF were purchased from ICN Biomedical and Sime Darby Malaysia, respectively. TRF used in current study consist of 25\% tocopherol and $75 \%$ tocotrienols with 95\% purity. Vitamin $\mathrm{E}$ was dissolved in $100 \%$ ethanol and freshly prepared in laminar air flow to maintain its sterility. Working concentration of vitamin $\mathrm{E}$ was kept at $0.1 \% \mathrm{v} / \mathrm{v}$ in culture media to avoid toxicity from ethanol. To achieve $0.1 \%$ of vitamin $\mathrm{E}$, volume to the total volume of medium, vitamin $\mathrm{E}$ was prepared in microgram $(\mu \mathrm{g})$ concentrations. The vial was wrapped with aluminium foil to protect from light and flushed with nitrogen gas to prevent from oxidation. Vitamin $\mathrm{E}$ was then stored at $4^{\circ} \mathrm{C}$ until further used. To determine the effect of vitamin $\mathrm{E}$ as an antioxidant, cell toxicity was induced with $\mathrm{IC}_{20}$ of glutamate followed by supplementation of 100,200 , and $300 \mathrm{ng} / \mathrm{mL}$ of TRF or $\alpha$-TCP for 24 hours in $5 \% \mathrm{CO}_{2}$ and $95 \%$ air. The cell viability was then assessed using MTT assay. The graph of cell viability against vitamin $\mathrm{E}$ treatment was plotted.

2.6. ROS Measurement. Cells were seeded in 24-well plates. On day 6 after neural cell plating, the cells were induced with $60 \mathrm{mM}$ of glutamate for 12 hours (based on data from the dose response and time course experiments) followed by treatment with 100,200 , or $300 \mathrm{ng} / \mathrm{mL}$ of either TRF or $\alpha$-TCP for an additional 24 hours. A commercially available DCFH-DA dye (OxiSelect $^{\mathrm{TM}}$ Intracellular ROS Assay Kit, Cell Biolabs) was used according to the manufacturer's instructions with slight modifications. DCFH-DA diffuses into cells and is deacylated by cellular esterase to the nonfluorescent molecule DCFH, which is rapidly oxidized to the highly fluorescent DCF in the presence of intracellular ROS; this shift in fluorescence is read by a fluorescence microplate reader. The treated cells were washed gently twice with Dulbecco's phosphate-buffered saline (DPBS, Gibco) before $200 \mu \mathrm{L}$ of DCFH-DA was added to the cells and incubated at $37^{\circ} \mathrm{C}$ for 1 hour. Then, the cells were washed twice with DPBS and $200 \mu \mathrm{L}$ of media was added to the cells followed by $200 \mu \mathrm{L}$ of $2 x$ Cell Lysis Buffer; the mixtures were incubated for 5 minutes. The mixture $(150 \mu \mathrm{L})$ was then transferred to a black 96-well plate, and the fluorescence was measured using a fluorometric plate reader (FLUOstar ${ }^{\circledR}$ Omega, BMG LABTECH) at $480 \mathrm{~nm} / 530 \mathrm{~nm}$ excitation/emission wavelengths. All the data are reported as the mean \pm SEM. For the statistical analysis, one-way ANOVA was used; comparisons with the control group were made using Dunnett's test (GraphPad Prism version 5, GraphPad Software). The statistical analysis was presented in Microsoft Excel.

2.7. Gene Expression Analysis. To determine the effect of vitamin $\mathrm{E}$ as an antioxidant, cell toxicity was induced by 12 hours incubation with $60 \mathrm{mM}$ glutamate, followed by supplementation of 100,200 , or $300 \mathrm{ng} / \mathrm{mL}$ of either TRF or $\alpha$-TCP for 24 hours in an atmosphere containing $5 \% \mathrm{CO}_{2}$ and $95 \%$ air. Total RNA was isolated using a FavorPrep ${ }^{\mathrm{TM}}$ Blood/Cultured Cell Total RNA Mini Kit (Favorgen). cDNA synthesis was performed using a qPCRBIO cDNA Synthesis kit (PCR Biosystems), and qRT-PCR was performed using qPCRBIO SyGreen Master Mix (PCR Biosystems), following the manufacturer's instructions. The following primer sequences were used: GluN1, forward AGTATGACTCCACTCACGG, reverse CATGGTGGTGAAGACACCAGT; GluK1, forward CTAATTCGTCTGCAAGAGCTCATC, reverse CTCCTTGCCTTTCTTCATCTCCTT; NSE, forward GATCTCTATACTGCCAAAGGTC, reverse GCCTAAGTAACGCTGTTTGTC; and GAPDH, forward CAGTATGACTCCACTCACGG, reverse CATGGTGGTGAAGACACCAGT. All the experiments were independently performed at least twice; within each experiment, all the conditions were technically repeated in triplicate. The qPCR data were normalized to the GAPDH values. All data are reported as the mean \pm SEM. For statistical analysis, one-way ANOVA was used, and comparisons to positive controls were made using Dunnett's test (GraphPad Prism version 5). Statistical analyses are presented in Microsoft Excel.

\section{Results}

3.1. Efficiency of the Neural Differentiation of 46C Cells. In this study, the transgenic mouse ES cell line $46 \mathrm{C}$ was used. The quality of the $46 \mathrm{C}$ cells was assessed to determine the efficiency of the neural differentiation of $46 \mathrm{C}$ cells. High-quality 46C cells exhibit an increased nucleus-cytoplasm ratio and a large nucleus with multiple nucleoli; these characteristics were successfully achieved in this study as shown in Figure 1. Upon removal of LIF and culture of 46C cells on a nonadhesive substratum dish, the cells proceeded to spontaneously 


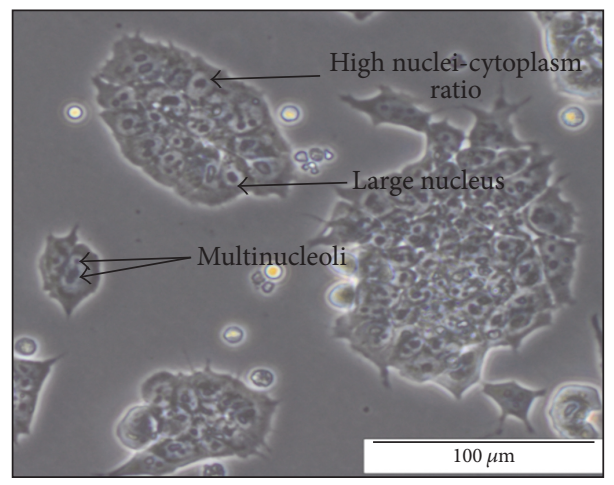

FIGURE 1: High-quality 46C cells exhibit an elevated nucleus-cytoplasm ratio and large nuclei with multiple nucleoli in culture.

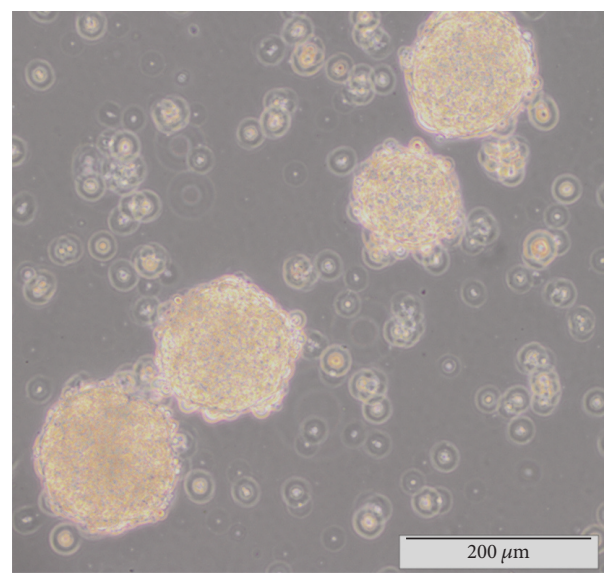

(a)

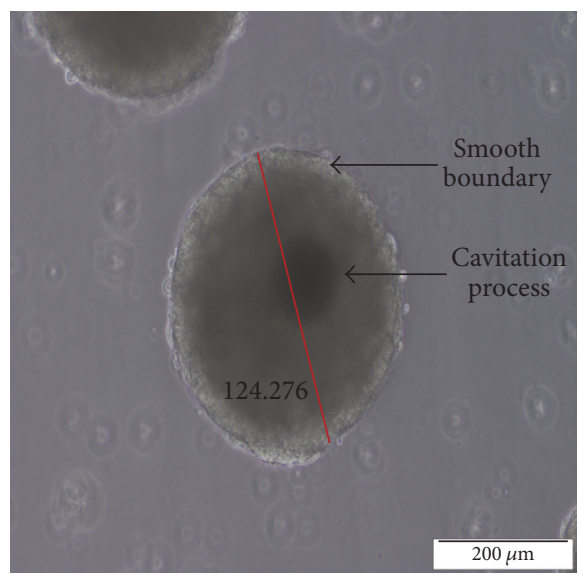

(b)

FiguRE 2: (a) 46C cells begin to form aggregates on day 2 after removal of LIF from the culture and grow on the nonadhesive substratum plate. (b) Mature EBs on day 6 after removal of LIF exhibit a clear and smooth boundary, are larger in size (124.279 $\mu \mathrm{m})$, and have begun the cavitation process.

differentiate and form EBs. On day 2 after removing LIF, the formation of EBs appeared as small aggregates with an irregular boundary as shown in Figure 2(a). Neural induction was then performed by the addition of $10 \mu \mathrm{M}$ all-transretinoic acid (ATRA) from day 4 to day 8 of culturing. On day 6, the EBs appeared mature with clear and smooth boundaries, were larger in size $(100-300 \mu \mathrm{m})$, and exhibited cavitation within the centre of the masses (Figure 2(b)). From day 5 onwards, the formation of NPCs was observed under a fluorescence microscope for expression of eGFP. On day 6, 2 days after the addition of ATRA, cells expressing eGFP were detected under a fluorescence microscope as shown in Figure 3(b).

3.1.1. Antigenic Characterization of Class III Beta-Tubulin. Class III $\beta$-tubulin is a microtubule component that is expressed in neuronal cells. After the dissociated eGFPpositive EBs were replated, the cells began to form a network of neural-like cells after two days. On day 6 after replating, a more prominent network showed neuron-like cells, and class III $\beta$-tubulin protein expression was assessed via immunocytochemistry. The cells were positive for class
III $\beta$-tubulin protein indicating the presence of postmitotic neurons (Figure 4).

3.1.2. Antigenic Characterization of Glial Fibrillary Acidic Protein (GFAP). GFAP is an intermediate filament (IF) protein that forms a network that provides support and strength to neurons. It is expressed in cells throughout the CNS, including astrocytes and glial cells. On day 6 after plating, the neural-like cells expressed GFAP, which is highly indicative of the presence of glial cells in the cultures of differentiated $46 \mathrm{C}$ cells (Figure 5).

3.2. Establishment of an In Vitro Oxidative Stress Model in a Neural-Derived 46C Cell Line. Glutamate induction was initially conducted in the presence of the N2/B27 supplement; however, the induction failed after many trials, and it was decided that N2/B27 supplementation impeded the glutamate induction. Successful induction was achieved after consistent withdrawal of N2/B27. Glutamate dose response and time course study was then carried out to determine glutamate concentration and time incubation to induced injury in neural-derived $46 \mathrm{C}$ cells followed by posttreatment 


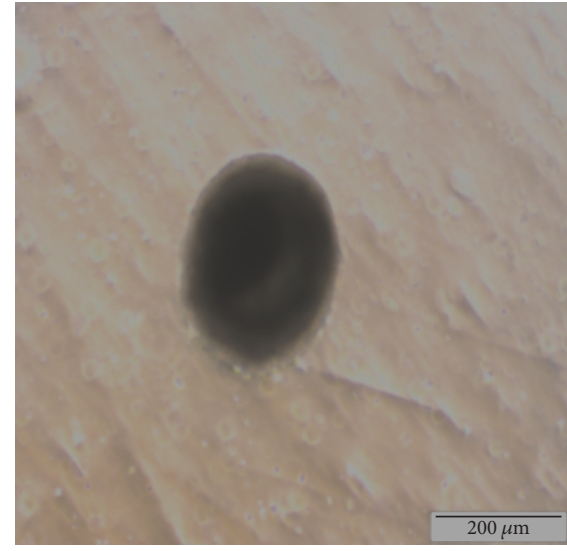

(a)

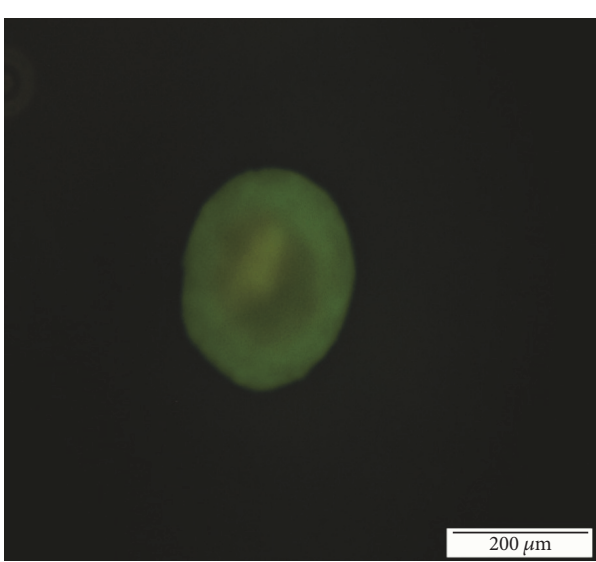

(b)

FIGURE 3: (a) Phase contrast image of day 6 EBs and the corresponding (b) fluorescence microscopy image showing eGFP expression, which clearly indicates the expression of Sox-1 and thus marks the presence of neural precursor cells (NPCs).

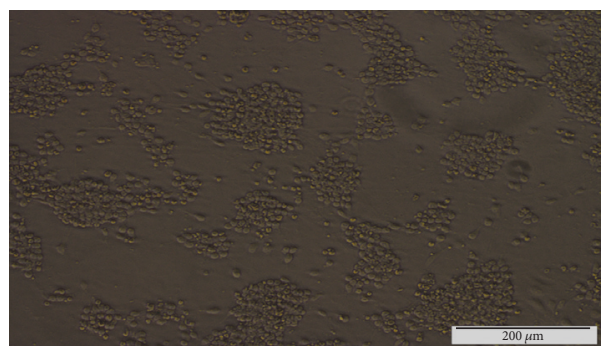

(a) Bright-field

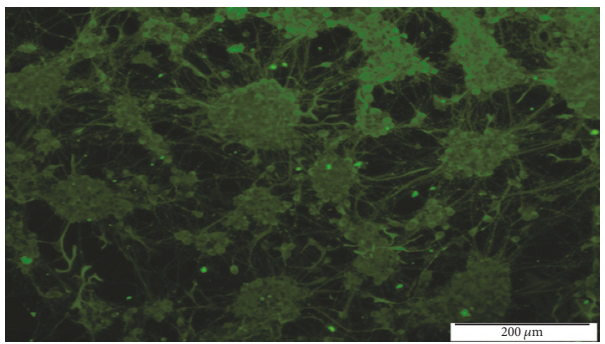

(c) Beta-tubulin

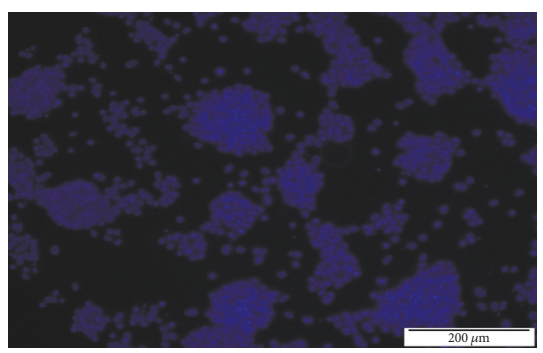

(b) DAPI

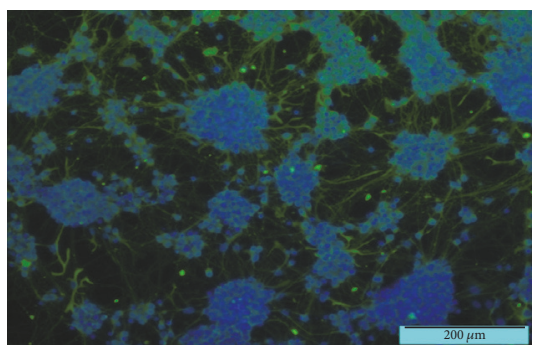

(d) Merge

FiguRE 4: Day 6 of neural postplating. (a) Phase contrast of neural-like cells on day 6 of neural postplating. (b) DAPI counterstaining corresponding to (a). (c) Immunofluorescence of class III $\beta$-tubulin corresponding to (a). (d) Merge of (b) and (c).

of vitamin $\mathrm{E}$ to determine the cell cytotoxicity of vitamin $\mathrm{E}$ using MTT assays.

3.2.1. Glutamate Dose Response Study. A dose response curve of glutamate was constructed to determine the tolerance concentration of neural cells derived from $46 \mathrm{C}$ cells against glutamate insults (Figure 6). The $\mathrm{IC}_{50}$ of glutamate toxicity to induce neural cell was determined; from this value, the $\mathrm{IC}_{20}$ was extrapolated and used to induce minimal injury to the neural cells. Figure 6 shows the toxicity of glutamate was dose dependent; with increasing glutamate concentrations, increasing cell death was observed. The $\mathrm{IC}_{50}$ and $\mathrm{IC}_{20}$ were approximately $125 \mathrm{mM}$ and $60 \mathrm{mM}$, respectively. Approximately $80 \%$ of the neural cells survived when induced with
$60 \mathrm{mM}$ glutamate; thus, this dosage was then used for the time course experiment as well as all subsequent experiments.

3.2.2. Glutamate Time Course Study. Time course study has been conducted in five time intervals: $0,4,8,12$, and 24 hours. The purpose of this study is to determine the incubation period of neural cells against glutamate excitotoxicity. Figure 7 shows incubation time for neural cells to reach $20 \%$ cell death with $60 \mathrm{mM}$ glutamate was approximately 12 hours.

From dose response and time course data, neural cells that derived from $46 \mathrm{C}$ cells were induced with oxidative stress by $60 \mathrm{mM}$ concentration of glutamate for 12 hours that caused $20 \%$ neuronal cell death to generate in vitro oxidative stress model. $\mathrm{IC}_{20}$ was used to induce minimal injury of the 


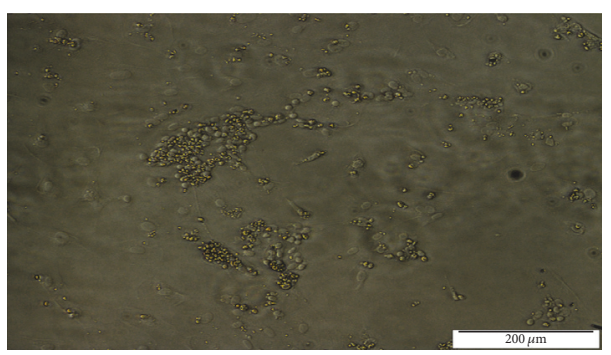

(a) Bright-field

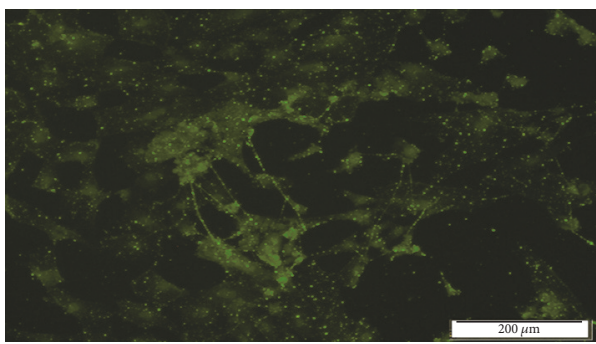

(c) GFAP

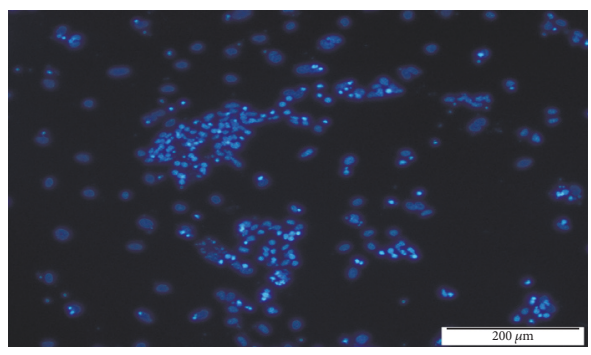

(b) DAPI

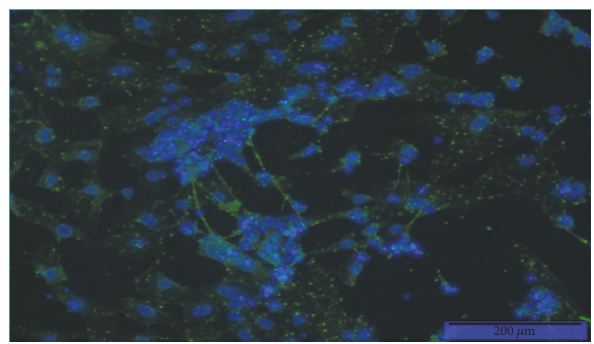

(d) Merge

Figure 5: Day 6 of neural postplating. (a) Phase contrast of neural-like cells on day 6. (b) DAPI nuclear counterstaining corresponding to (a). (c) Immunofluorescence of GFAP staining corresponding to (a). (d) Merge of (b) and (c).

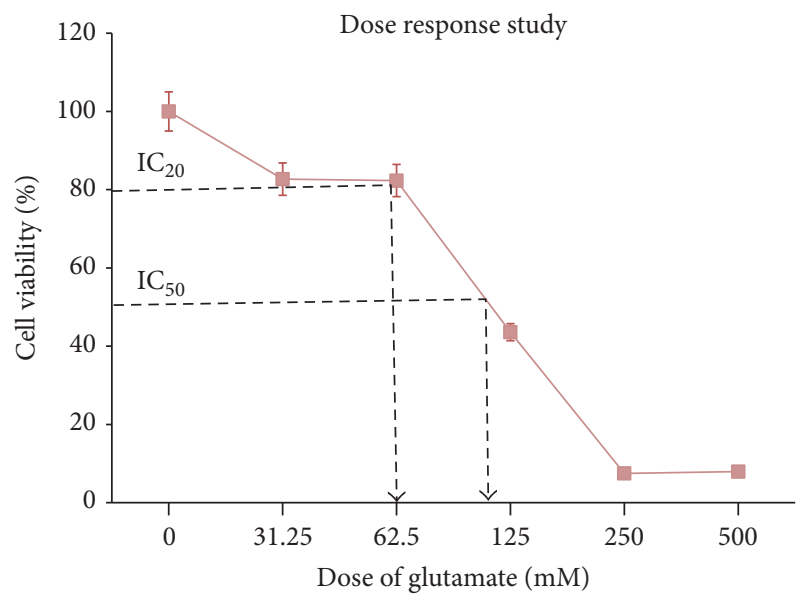

Figure 6: Graph of various glutamate concentrations against cell viability. Cell viability $(\%)$ is the mean \pm SEM of three independent experiments ( $n=3$ in each experiment).

cells; thus prophylactic effects of TRF and $\alpha$-TCP treatment can be determined [10]. $\mathrm{IC}_{20}$ was further used in the entire study whereby the cell was designed to only achieve minimal stress. Although the glutamate concentration used to induce neuronal cell injury is high, this concentration is optimal for the setup of this study due to the various sensitivities and resistance to glutamate within the mixed culture.

\subsubsection{Effect of Posttreatment with Vitamin E on Glutamate-} Induced Neural-Like Cells Derived from 46C Cells. The potential of vitamin $\mathrm{E}$ in treating the cells after being exposed to high concentration of glutamate was elucidated as in

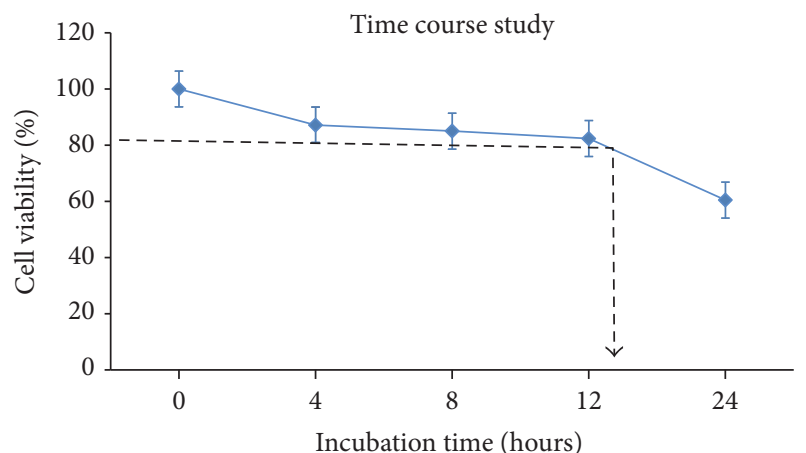

FIGURE 7: Graph of incubation time against cell viability. Cell viability (\%) is the mean \pm SEM of three independent experiments ( $n=3$ in each experiment).

Figure 8. Neural-derived 46C cells were exposed to $60 \mathrm{mM}$ of glutamate for 12 hours. Two different types of vitamin $\mathrm{E}$ (TRF and $\alpha$-TCP) of several concentrations (100, 200, and $300 \mathrm{ng} / \mathrm{ml}$ ) were added to cells. Then the cells were subjected to MTT assay to assess the cell viability.

Twenty percent of cell death occurs in positive control cells upon exposure to $60 \mathrm{mM}$ glutamate. When increased concentrations of TRF were added to the cells from 100 to $300 \mathrm{ng} / \mathrm{mL}$, the cell viability was gradually increased. Nevertheless, this increase was insignificant. Similarly, treatment with $\alpha$-TCP also did not show any significant effects. Treatment with TRF and $\alpha$-TCP $(100,200$, and $300 \mathrm{ng} / \mathrm{ml})$ for 24 hours does not give any toxic effect to our neural cell culture. Thus, $100-300 \mathrm{ng} / \mathrm{ml}$ of TRF and $\alpha$-TCP were further 


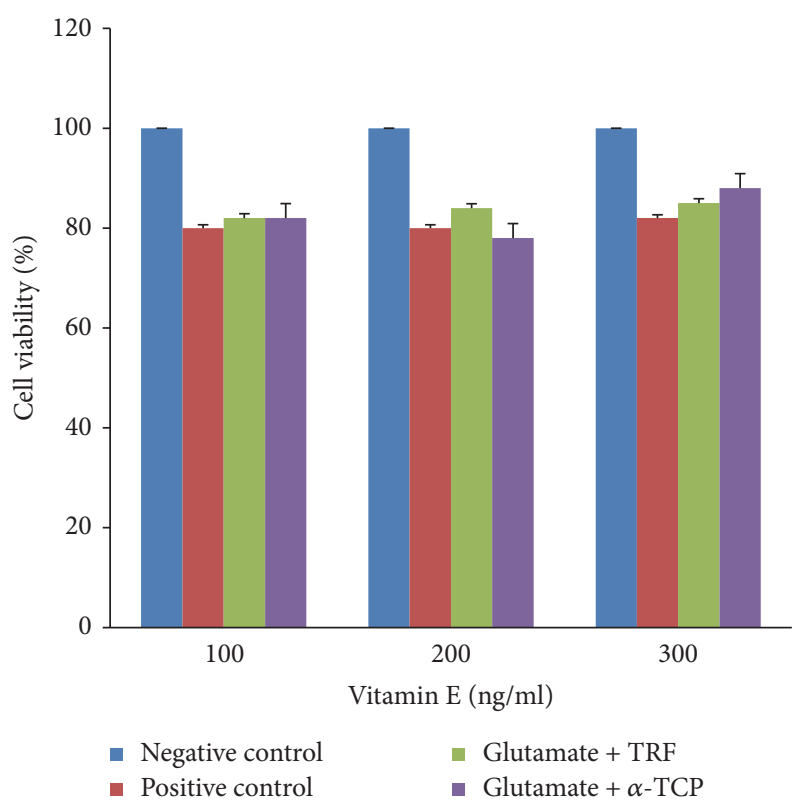

FIGURE 8: Effects of posttreatment with vitamin $\mathrm{E}$ on neuralderived 46C cells injured with $60 \mathrm{mM}$ glutamate for 12 hours before being treated with $100-300 \mathrm{ng} / \mathrm{ml}$ of TRF and $\alpha$-TCP for 24 hours (posttreatment). Data are the mean \pm SEM of three independent experiments $\left(n=3\right.$ per experiment). ${ }^{*} P<0.05$ compared with negative control; ${ }^{\Delta} P<0.05$ compared with positive control.

used to investigate the potential of vitamin $\mathrm{E}$ in treating glutamate-injured neural cells.

\subsection{Effect of Vitamin E on Scavenging Glutamate-Induced ROS} in Neural-Like Cells Derived from 46C Cells. The posttreatment study was conducted to elucidate the potential of vita$\min \mathrm{E}$ to reduce ROS production in glutamate-injured neural cells. Figure 9 shows that the glutamate insult increased the production of ROS approximately elevenfold in the positive control (Cells $+60 \mathrm{mM}$ glutamate) compared to that in the untreated group (negative control; cell + ethanol).

Regarding the TRF and $\alpha$-TCP treatments, both isomers exerted a similar effect in response to the glutamate toxicity in neural-like cells derived from $46 \mathrm{C}$ cells. There were approximately $61.1 \%, 52.7 \%$, and $33.05 \%$ decreases of ROS production upon supplementation of $100-300 \mathrm{ng} / \mathrm{mL}$ of TRF, respectively, compared to positive control. Meanwhile, treatment of 100,200 , and $300 \mathrm{ng} / \mathrm{mL}$ of $\alpha$-TCP decreased the ROS production by approximately $67.1 \%, 60 \%$, and $57.2 \%$, respectively, compared to positive control.

ROS production was greatest in the positive control compared to the production in the TRF and $\alpha$-TCP-treated samples. Furthermore, there were significant differences in ROS production among the 100, 200, and $300 \mathrm{ng} / \mathrm{mL}$ TRF treatment groups compared with the positive control group. Treatment with $\alpha$-TCP also shows significant differences at concentrations of 200 and $300 \mathrm{ng} / \mathrm{mL}$ compared with the positive control. Additionally, TRF exhibited a more marked reduction of ROS levels compared to $\alpha$-TCP.

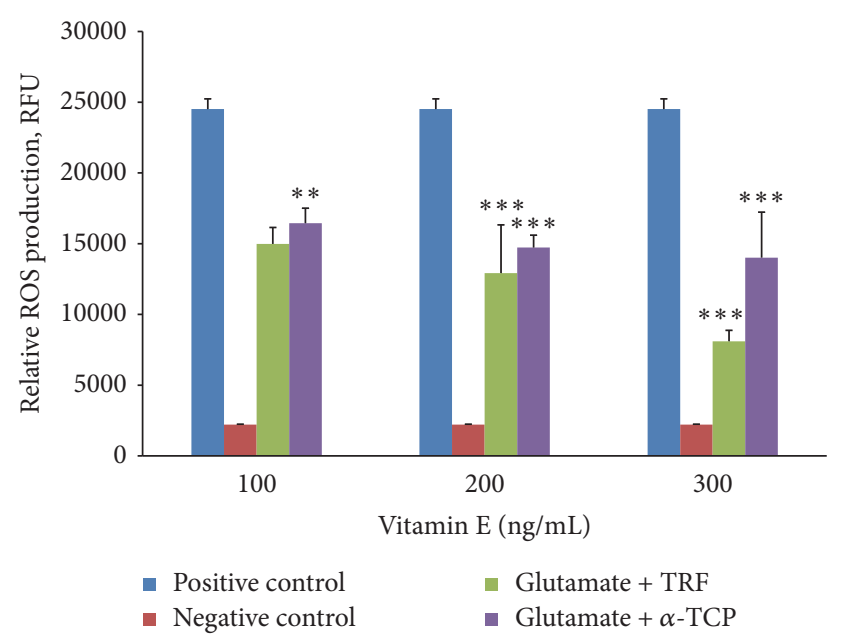

FIGURE 9: Posttreatment effect of TRF and $\alpha$-TCP on neurallike cells derived from $46 \mathrm{C}$ cells injured with $60 \mathrm{mM}$ glutamate. Injured cells ( $60 \mathrm{mM}$ glutamate for 12 hours) were posttreated with $100-300 \mathrm{ng} / \mathrm{mL}$ TRF or $\alpha$-TCP and incubated for another 24 hours. RFU is the relative fluorescence unit where the value is the mean \pm SEM of three independent experiments ( $n=3$ per experiment). ${ }^{* *} P<0.01$ and ${ }^{* * *} P<0.001$, vitamin E-treated group versus the positive control group.

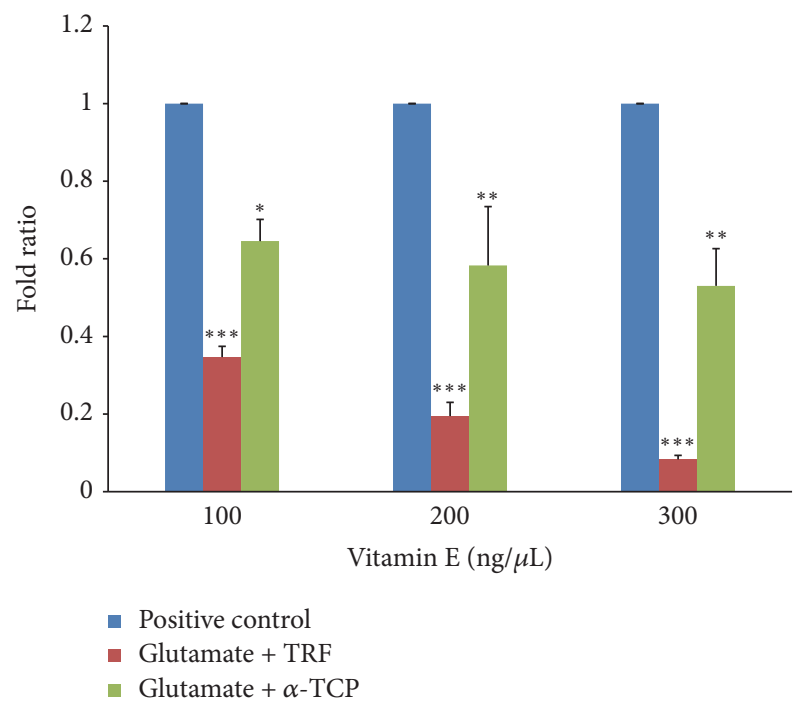

FIGURE 10: GluN1 expression in neural cells derived from 46C cells after glutamate challenge and posttreatment with vitamin $\mathrm{E}$. The fold change of GluN1 was normalized to GAPDH levels. Data are presented as the mean \pm SEM of three independent experiments. ${ }^{*} P<0.05,{ }^{* *} P<0.01$, and ${ }^{* * *} P<0.001$, vitamin E-treated group versus the positive control group.

\subsection{Effects of Vitamin E on the Gene Expression of Glutamate Receptors and Neuron-Specific Enolase}

3.4.1. Glutamate Receptor, NMDA-1 (GluN1). In the posttreatment study, $60 \mathrm{mM}$ glutamate increased level of injury as indicated by increased GluN1 expression in the neural cells treated with glutamate (Figure 10). However, supplementation of 100,200 , and $300 \mathrm{ng} / \mathrm{mL}$ TRF in cells exposed to 


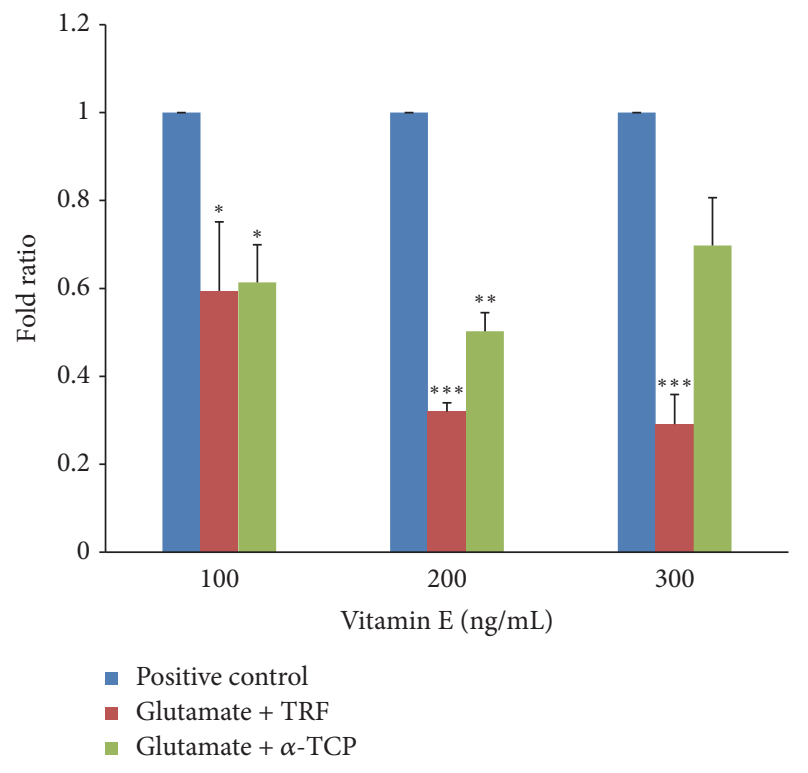

FIGURE 11: GluK1 expression in neural cells derived from 46C cells after glutamate challenge and posttreatment with vitamin $\mathrm{E}$. The fold change of GluK1 was normalized to GAPDH levels. Data are expressed as the mean \pm SEM of three independent experiments. ${ }^{*} P<0.05,{ }^{* *} P<0.01$, and ${ }^{* * *} P<0.001$, vitamin E-treated group versus the positive control group.

glutamate toxicity significantly decreased the levels of GluN1 expression with fold ratios of $0.347 \pm 0.03,0.195 \pm 0.04$, and $0.083 \pm 0.01$, respectively. Posttreatment with $\alpha$-TCP also significantly decreased GluN1 expression with fold ratios of $0.646 \pm 0.06,0.583 \pm 0.1$, and $0.530 \pm 0.09$, respectively. Despite the significantly decreased GluN1 expression in the $\alpha$-TCPtreated group, the reduction was only between 40 and $50 \%$. However, the reduction in response to TRF supplementation achieved nearly $90 \%$ in the cells treated with $300 \mathrm{ng} / \mathrm{mL}$ TRF. When comparing these two isomers of vitamin E, TRF was more effective than $\alpha$-TCP in suppressing GluN1 expression.

3.4.2. Glutamate Receptor, Kainate 1 (GluK1). Figure 11 shows that, upon supplementation with $100-300 \mathrm{ng} / \mathrm{mL}$ TRF, there was a significant decline in GluK1 expression with fold ratios of $0.594 \pm 0.16,0.320 \pm 0.02$, and $0.291 \pm 0.07$, respectively, compared to the positive control. Treatment with $\alpha$-TCP shows a significant difference in GluK1 expression at 100 and $200 \mathrm{ng} / \mathrm{mL}$ with fold ratios $0.614 \pm 0.09$ and $0.502 \pm 0.04$, respectively. Overall, $200 \mathrm{ng} / \mathrm{mL}$ of either vitamin E isomer elicited the best protection against glutamate insults.

3.4.3. Neuron-Specific Enolase (NSE). In neural cells derived from $46 \mathrm{C}$ cells, treatment with $60 \mathrm{mM}$ glutamate significantly increased the level of injury as detected by the increased levels of NSE expression. Figure 12 shows that, upon supplementation with TRF at $100-300 \mathrm{ng} / \mathrm{mL}$, the NSE expression fold ratios were significantly decreased compared to the positive control; these ratios were $0.525 \pm 0.03,0.514 \pm 0.02$, and $0.605 \pm$ 0.11 , respectively. Upon treatment with $100-300 \mathrm{ng} / \mathrm{mL} \alpha$ TCP, the NSE expression fold ratios in glutamate-injured

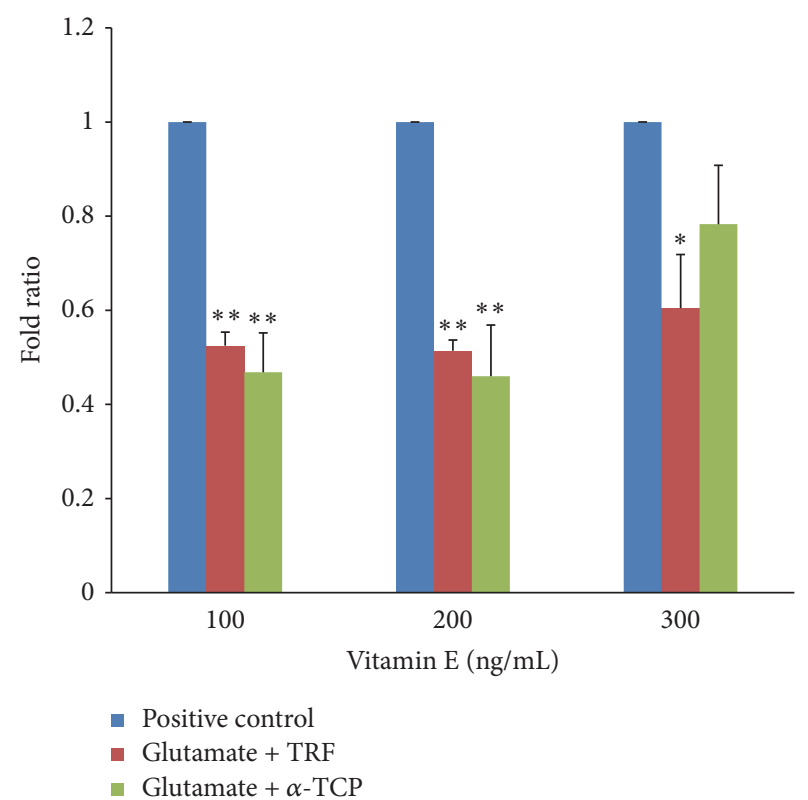

FIGURE 12: NSE expression in neural cells derived from 46C cells after glutamate challenge and posttreatment with vitamin $\mathrm{E}$. The fold change of NSE was normalized to GAPDH levels. Data are presented as the mean \pm SEM of three independent experiments. ${ }^{*} P<0.05$ and ${ }^{* *} P<0.01$, vitamin E-treated group versus the positive control group.

neural cells were $0.468 \pm 0.08,0.460 \pm 0.1$, and $0.782 \pm$ 0.12 , respectively. A significant reduction of NSE expression as an injury marker was achieved by supplementation with $100-200 \mathrm{ng} / \mathrm{mL}$ of either TRF or $\alpha$-TCP.

\section{Discussion}

4.1. In Vitro Oxidative Stress Model. The 46C cell line used in this study is a transgenic mouse embryonic stem (ES) cell that was transduced with the eGFP gene inserted into the Sox1 open reading frame [11]. In this study, Sox-1, which is the earliest marker for NPCs, was used to directly monitor the differentiation of $46 \mathrm{C}$ cells under a fluorescence microscope by observing eGFP expression in live cells from 46C EBs. Sox-1 is not expressed in undifferentiated ES cells but it is primarily expressed in NPCs upon differentiation of ES cells into a neural lineage [12]. Our findings show that eGFP expression was first detected in 46C EBs on day 6 after neural induction, which indicates the appearance of NPCs in our cultures. A study conducted by Nordin et al. [13] used fluorescence activated cell sorting (FACS) to reveal that that few cells express SoxleGFP before day 4 and that eGFP expression peaks at approximately day 8 in the same cell line.

The present study exhibits the successful differentiation of the $46 \mathrm{C}$ cell line into a neural lineage using $4-/ 4+$ protocols with RA as an inducer in the EBs suspension to stimulate neural differentiation. Serum-free media supplemented with $\mathrm{N} 2$ and B27 were also used to trigger neural lineages from the $46 \mathrm{C}$ cell line. This study revealed the presence of a major population of class III $\beta$-tubulin-positive cells and a small 
population of GFAP-positive cells in the cultures. Throughout the experiment, the composition of the cell types after day 6 of neural cell postplating was approximately $80-90 \%$ neurons and the remainder were glial cells. The mixed population of neuronal and glial cells in the culture is advantageous because it more closely recapitulates the synergistic effects between glial cells and neurons against neurotoxicity. A study conducted by Kim et al. [14] showed using the same protocol with serum-free medium that a high percentage of class III $\beta$ tubulin-positive cells concomitant with GFAP-positive cells appeared after 6 days of neural postplating in which the primary population was neurons (approximately 60-70\%) and the remainder are glial cells. In addition, Bibel et al. [15] showed that approximately $85 \%$ of the cells were class III $\beta$-tubulin-positive cells with a homogenous appearance of neuronal cell bodies.

In principle, the physiological properties of ES cellderived neurons are similar to primary neurons with the presence of glutamate receptors and transporters. These neurons can express voltage-gated calcium channels and glutamate receptors such as NMDA and the kainate receptor (David and James, 1999). Neurons derived from ES cells can also use glutamate as a neurotransmitter as reported by Bibel et al. [15], who showed that approximately $93 \pm 4.7 \%$ of the cells were positive for vGlutl, a vesicular glutamate transporter expressed on the surface membrane of neurons derived from ES cells. Based on this accomplishment, neurons derived from the $46 \mathrm{C}$ cell line offer distinct advantages over other neuron-based cell cultures as an in vitro model system for investigating nutritional therapy in the prevention or mitigation of $\mathrm{AD}$ progression.

The ability of $46 \mathrm{C}$ cells to form EBs and express e GFP and other neural protein markers denoted the successful implementation and efficiency of the neural differentiation of $46 \mathrm{C}$ cells. These neural cell cultures were used as a model of oxidative stress to determine the antioxidant activity of vitamin $\mathrm{E}$ on modulating the expression of glutamate receptors and other markers of neuronal injury.

4.2. Glutamate Excitotoxicity. In the CNS, glutamate is a major neurotransmitter involved in cognition, memory, and learning [16]. Elevated levels of glutamate can cause glutamate excitotoxicity in neurons and eventually promote a state of oxidative stress. Glutamate excitotoxicity has been shown to contribute to the pathogenesis of neurodegenerative diseases including $\mathrm{AD}[17,18]$. Oxidative stress occurs due to an imbalance of prooxidant production and antioxidant defence molecules in the body to detoxify the free radicals.

The presence of glial cells (primarily astrocytes) in cell culture can strengthen the neurons and combat the effects of elevated glutamate concentrations. Despite the protection conferred by glial cells against glutamate toxicity, a study conducted by Gupta et al. [19] showed that glutamate toxicity can be induced in a mixed culture of neural cells derived from ES cells by incubating the cells with deprived medium. In parallel, our study revealed that administration of glutamate at a millimolar concentration to cells in the presence of $\mathrm{N} 2$ and B27 supplements in the medium failed to induce oxidative stress injury. There are two likely reasons for this response: first, the N2/B27 supplements contain an antioxidant that can neutralize the glutamate toxicity, and second glial cells can provide support against injury. Thus, instead of removing the glial cells from the culture, the N2/B27 supplement was eliminated from the differentiation medium the day before administration of the glutamate treatment to create a nutrient-deficient environment for the cells. Successful induction with $\mathrm{IC}_{20}$ of glutamate was then achieved after consistent withdrawal of N2/B27.

In this study, the neural cells were exposed to few concentrations of glutamate and cell viability was assessed to determine the cell response to glutamate excitotoxicity. It was expected that the cell viability would drop significantly when exposed to high concentrations of glutamate. Previous observation found that the exposure of HT4 and HT22 neuronal cells to $10 \mathrm{mM}$ glutamate reduced the cells viability by more than $90 \%$ in 24 hours (Sen et al., 2000) [20]. From dose response and time course data, neural cells that derived from $46 \mathrm{C}$ cells were induced with oxidative stress by $60 \mathrm{mM}$ concentration of glutamate for 12 hours that caused $20 \%$ neuronal cell death to generate in vitro oxidative stress model.

To assess the neurorecovery properties of vitamin $\mathrm{E}$ against glutamate injury, the posttreatment study was conducted. Various concentrations $(100-300 \mathrm{ng} / \mathrm{ml})$ of TRF and $\alpha$-TCP were given to the cells after being exposed to $60 \mathrm{mM}$ glutamate. TRF which consist of $75 \%$ tocotrienols and $25 \%$ tocopherol were compared with $\alpha$-TCP. The cells viability was later determined by using the MTT assay. Present finding has shown that viability of neural-derived $46 \mathrm{C}$ cells was reduced approximately by $20 \%$ when exposed to $60 \mathrm{mM}$ glutamate for 12 hours. Posttreatment with TRF increased steadily when the concentrations of TRF given increased from 100 to $300 \mathrm{ng} / \mathrm{mL}$. Although there was no significant difference when compared to the positive control ( $60 \mathrm{mM}$ glutamate), this result showed that the posttreatment with TRF thus improved cells viability. On the other hand, posttreatment of neural cells with $\alpha$-TCP also produced no significant effect along 100-300 $\mathrm{ng} / \mathrm{ml}$ concentrations when compared to positive control.

Although the results shown were not significant, TRF exhibited better potential than $\alpha$-TCP which indicates its capability to be used in neurorecovery of injured neural cells. TRF might be able to help the cells recovery after being injured with high concentrations of glutamate. However, MTT assay was mostly used for screening purposes only as it only measures the activity of mitochondrial dehydrogenase in the cells. Therefore, more detailed studies need to be conducted to verify the effects of TRF to reduce the oxidative stress in the neural cells, hence leading to understanding its neuroprotective potential. Thus, in this present study ROS measurement was conducted.

Generally, ROS are formed as a natural byproduct during normal aerobic-based energy metabolism in cells and are safely eradicated by biological antioxidants. Typically, cells have their own protective mechanism against ROS via upregulation of antioxidant molecules such as glutathione, catalase, superoxide dismutase, and glutathione peroxidase to counteract ROS toxicity [21]. The influx of a high concentration of glutamate inhibits the conversion of glutamate and 
cysteine into glutathione (an antioxidant molecule) through the antiporter system $\mathrm{x}_{\mathrm{c}}{ }^{-}$[20], which suggests that glutamate excitotoxicity can cause oxidative insults by decreasing the production of antioxidant molecules that can start a chain reaction of free radical attack and eventually result in the disruption of a living cell.

In addition, glutamate excitotoxicity is due to the overstimulation of glutamate receptors-primarily ionotropic glutamate receptors (iGluRs). This current study focused on the gene expression of two iGluRs: GluN1, which encodes the NMDA receptor subunit 1, and GluK1, which encodes the kainate receptor subunit 1 . The results of our experiments indicate that after a 12-hour incubation with $60 \mathrm{mM}$ glutamate, neural cells exhibited markedly increased GluN1 and GluK1 expression; excessive stimulation of these receptors mediates calcium ion-dependent cell death [22]. This finding proved that our neural cells derived from 46C cells expressed mRNA for the NMDA and kainate receptors upon incubation with a significant concentration of glutamate. In comparison, according to Gupta et al. [19], an elevated concentration of glutamate can cause overactivation of the NMDA receptor, which leads to cell death in neural cells derived from human embryonic stem cells.

A previous study showed that overactivation of the NMDA and kainate receptors by high concentrations of glutamate caused an excess influx of calcium ions into the cells, which initiates the generation of $\operatorname{ROS}[4,5,23]$. Accumulation of calcium ions in the cytosol triggers the depolarization of the mitochondrial permeability transition pore (MTP) that allows the entry of calcium into the mitochondrial membrane and consequently causes the mitochondria to swell and rupture. This action releases the ROS content from the mitochondria into the cytosol and contributes to the high level of ROS in the cytosol during glutamate excitotoxicity.

This study also showed that ROS production in cells injured by excessive glutamate increased approximately elevenfold after a 12-hour incubation compared to untreated cells (negative control). Mouse hippocampal HT22 neuronal cells exhibited more than fivefold increase in ROS production after a 6-hour incubation with $5 \mathrm{mM}$ glutamate [24]. Our finding demonstrates that glutamate is tightly associated with ROS generation in neural cell cultures.

Additionally, another hallmark of neuronal injury is the expression of NSE. The current study showed that NSE expression was significantly increased in neural cells derived from $46 \mathrm{C}$ cells upon glutamate treatment, which indicates successful injury in the culture. According to Martin et al. [25], neurons upregulated NSE expression upon neuronal injury due to the high ATP requirements to overcome the injury. During periods of neuronal injury, more glucose is converted to pyruvate via glycolysis to generate more ATP to be utilized by injured cells. This study suggests that the upregulation of NSE expression during glutamate insult in this experiment is an effort to promote survival in response to glutamate injury.

4.3. Neurorecovery of Vitamin E against Glutamate Excitotoxicity. Vitamin E exhibits strong antioxidant potential that can inhibit the reactivity of ROS or free radicals. Additionally, a few in vitro studies reported that vitamin $\mathrm{E}$ possesses neuroprotective effects in neurons and astrocytes $[2,10,26]$. In this present study, TRF and $\alpha$-TCP were administered at 100,200 , and $300 \mathrm{ng} / \mathrm{mL}$ to determine the ability of these isomers to scavenge ROS and modulate the expression of glutamate receptors and neuron-specific enolase, a marker of neuronal injury.

This present study demonstrates that glutamic excitotoxicity caused neuronal injury via ROS generation. Clearly, vitamin $\mathrm{E}$ in the form of TRF and $\alpha$-TCP could reduce the ROS levels in neural cells derived from $46 \mathrm{C}$ cells that were subjected to glutamate-induced oxidative stress. Both vitamin $\mathrm{E}$ isomers function in a dose-dependent manner and demonstrated a neuroprotective effect due to their strong antioxidant activity. Our data showed that treatment with $100-300 \mathrm{ng} / \mathrm{mL}$ vitamin E after a 12-hour induction of glutamate toxicity significantly reduced the generation of ROS, which suggests that the glutamate toxicity causes ROSmediated cell death and that vitamin E exerted antioxidant potential in neutralizing ROS reactivity.

Furthermore, the current study indicates that supplementation of $100-300 \mathrm{ng} / \mathrm{mL}$ of either TRF or $\alpha$-TCP significantly reduced the overexpression of GluN1 and GluK1 in neural cells subjected to glutamate-induced injury suggesting that vitamin E can potentially modulate glutamate receptor expression and decrease glutamate receptor toxicity. The role of vitamin $\mathrm{E}$ in the recovery of glutamate-injured neural cells was also assessed by measuring NSE gene expression. After posttreatment with vitamin E, the NSE expression levels significantly dropped in neural cells subjected to glutamate toxicity; doses of 100 and $200 \mathrm{ng} / \mathrm{mL}$ of either TRF or $\alpha$-TCP exhibited the best neuroprotection against neuronal injury. This result suggests that both TRF and $\alpha$-TCP can improve the survival of injured neural cells at a concentration as low as $100 \mathrm{ng} / \mathrm{mL}$. However, an effective dosage is crucial for vitamin $\mathrm{E}$ to exert its beneficial effects, and postinduction administration of $300 \mathrm{ng} / \mathrm{mL}$ vitamin $\mathrm{E}$ was not as effective as either 100 or $200 \mathrm{ng} / \mathrm{mL}$. When both isomers were compared, TRF consistently conferred better neuroprotection than $\alpha$ TCP in three independent experiments. These results are in agreement with a previous study demonstrating that tocotrienol better protects cells against glutamate-induced injury compared to tocopherol $[1,10]$.

\section{Conclusion}

The 46C cell line has been successfully used to monitor neural commitments and differentiate into neural cells. Neural differentiation using the single-cell suspension method via the formation of EBs has been shown to efficiently monitor neural differentiation and produce a mixed culture of neurons and glial cells; furthermore, this process has been used to create an oxidative stress model by treating the mixed neural-based cultures with a high concentration of glutamate. The gene expression assay clearly indicated that glutamate receptors (NMDA and kainate receptor) are involved in glutamate excitotoxicity and contribute to oxidative damage of neural cells derived from $46 \mathrm{C}$ cells. Alternatively, neural cells have their own protective mechanism towards glutamate 
toxicity via increased expression of NSE, an enzyme critical for glycolysis. The analysis of gene expression revealed that the upregulation of NSE is due to increased ATP demand for the neurorecovery process. Upon supplementation with one of two isomers of vitamin E, the ROS levels dropped significantly. Additionally, supplementation with vitamin $\mathrm{E}$ suppressed the expression of both tested glutamate receptors as well as NSE, which promoted the survival of neural cells derived from $46 \mathrm{C}$ cells.

\section{Abbreviations}

AD: Alzheimer's diseases

ATRA: All-trans-retinoic acid

EBs: Embryoid bodies

ES: Embryonic stem

ESM: Embryonic stem cell medium

eGFP: Enhanced green fluorescence protein

GFAP: Glial fibrillary acidic protein

LIF: Leukaemic inhibitory factor

NPC: Neural progenitor cell

ROS: Reactive oxygen species

RA: Retinoic acid

TRF: Tocotrienol-rich fraction

$\alpha$-TCP: Alpha-tocopherol.

\section{Conflicts of Interest}

The authors declare that there are no conflicts of interest regarding the publication of this paper.

\section{Acknowledgments}

This research was financially supported by the Putra Graduate Initiative (Vote 9464900) at Universiti Putra Malaysia.

\section{References}

[1] C. K. Sen, S. Khanna, and S. Roy, "Tocotrienols: vitamin E beyond tocopherols," Life Sciences, vol. 78, no. 18, pp. 20882098, 2006.

[2] F. Osakada, A. Hashino, T. Kume, H. Katsuki, S. Kaneko, and A. Akaike, " $\alpha$-Tocotrienol provides the most potent neuroprotection among vitamin E analogs on cultured striatal neurons," Neuropharmacology, vol. 47, no. 6, pp. 904-915, 2004.

[3] S. C. Khor, A. M. Razak, W. Z. Wan Ngah, Y. A. Mohd Yusof, N. Abdul Karim, and S. Makpol, "The tocotrienol-rich fraction is superior to tocopherol in promoting myogenic differentiation in the prevention of replicative senescence of myoblasts," PLoS ONE, vol. 11, no. 2, Article ID e0149265, 2016.

[4] W. R. Markesbery, "Oxidative stress hypothesis in Alzheimers disease," Free Radical Biology Medicine, vol. 23, no. 1, pp. 134147, 1997.

[5] A. A. Dayem, H.-Y. Choi, J.-H. Kim, and S.-G. Cho, "Role of oxidative stress in stem, cancer, and cancer stem cells," Cancers, vol. 2, no. 2, pp. 859-884, 2010.

[6] F. Fathi, T. Altiraihi, S. J. Mowla, and M. Movahedin, "Formation of embryoid bodies from mouse embryonic stem cells cultured on silicon-coated surfaces," Cytotechnology, vol. 59, no. 1, pp. 11-16, 2009.
[7] K. Guan, H. Chang, A. Rolletschek, and A. M. Wobus, "Embryonic stem cell-derived neurogenesis: Retinoic acid induction and lineage selection of neuronal cells," Cell and Tissue Research, vol. 305, no. 2, pp. 171-176, 2001.

[8] L. Gao, A. Syahril, and R. Rozita, "Neural commitment of embryonic stem cells through the formation of embryoid bodies (EBs)," Malaysian Journal of Medical Sciences, vol. 21, no. 5, pp. 8-16, 2014.

[9] G. Bain, D. Kitchens, M. Yao, J. E. Huettner, and D. I. Gottlieb, "Embryonic stem cells express neuronal properties in vitro," Developmental Biology, vol. 168, no. 2, pp. 342-357, 1995.

[10] T. R. Selvaraju, H. Khaza, S. Vidyadaran, M. S. A. Mutalib, and R. Vasudevan, "The neuroprotective effects of tocotrienol rich fraction and alpha tocopherol against glutamate injury in astrocytes," Bosnian Journal of Basic Medical Sciences, vol. 14, no. 4, pp. 195-204, 2014.

[11] J. Aubert, M. P. Stavridis, S. Tweedie et al., "Screening for mammalian neural genes via fluorescence-activated cell sorter purification of neural precursors from Soxl-gfp knock-in mice," Proceedings of the National Academy of Sciences of the United States of America, vol. 100, no. 1, pp. 11836-11841, 2003.

[12] Li, Lineage Selection for Generation and Amplification of Neural Precursor Cells, vol. 185, Springer, 2002, 205-215.

[13] N. Nordin, M. Li, and J. O. Mason, "Expression profiles of Wnt genes during neural differentiation of mouse embryonic stem cells," Cloning and Stem Cells, vol. 10, no. 1, pp. 37-47, 2008.

[14] M. Kim, A. Habiba, J. M. Doherty, J. C. Mills, R. W. Mercer, and J. E. Huettner, "Regulation of mouse embryonic stem cell neural differentiation by retinoic acid," Developmental Biology, vol. 328, no. 2, pp. 456-471, 2009.

[15] M. Bibel, J. Richter, K. Schrenk et al., "Differentiation of mouse embryonic stem cells into a defined neuronal lineage," Nature Neuroscience, vol. 7, no. 9, pp. 1003-1009, 2004.

[16] K. Tanaka, "Functions of glutamate transporters in the brain," Neuroscience Research, vol. 37, no. 1, pp. 15-19, 2000.

[17] A. L. Sheldon and M. B. Robinson, "The role of glutamate transporters in neurodegenerative diseases and potential opportunities for intervention," Neurochemistry International, vol. 51, no. 6-7, pp. 333-355, 2007.

[18] C. P. Zoia, E. Tagliabue, V. Isella et al., "Fibroblast glutamate transport in aging and in $\mathrm{AD}$ : Correlations with disease severity," Neurobiology of Aging, vol. 26, no. 6, pp. 825-832, 2005.

[19] K. Gupta, G. E. Hardingham, and S. Chandran, "NMDA receptor-dependent glutamate excitotoxicity in human embryonic stem cell-derived neurons," Neuroscience Letters, vol. 543, pp. 95-100, 2013.

[20] J. Lewerenz, S. J. Hewett, Y. Huang et al., “The cystine/glutamate antiporter system x c - in health and disease: from molecular mechanisms to novel therapeutic opportunities," Antioxidants and Redox Signaling, vol. 18, no. 5, pp. 522-555, 2013.

[21] C. Behl, J. B. Davis, R. Lesley, and D. Schubert, "Hydrogen peroxide mediates amyloid $\beta$ protein toxicity," Cell, vol. 77, no. 6, pp. 817-827, 1994.

[22] R. Dingledine, K. Borges, D. Bowie, and S. F. Traynelis, "The glutamate receptor ion channels," Pharmacological Reviews, vol. 51, no. 1, pp. 7-61, 1999.

[23] B. Uttara, A. V. Singh, P. Zamboni, and R. T. Mahajan, "Oxidative stress and neurodegenerative diseases: a review of upstream and downstream antioxidant therapeutic options," Current Neuropharmacology, vol. 7, no. 1, pp. 65-74, 2009. 
[24] J. S. Ha and S. S. Park, "Glutamate-induced oxidative stress, but not cell death, is largely dependent upon extracellular calcium in mouse neuronal HT22 cells," Neuroscience Letters, vol. 393, no. 2-3, pp. 165-169, 2006.

[25] F. Martin, R. Mergl, B. Stach, I. Jahn, H. Gertz, and P. Schönknecht, "Neuroscience Letters Elevated levels of cerebrospinal fluid neuron-specific enolase (NSE) in Alzheimer's disease," in Neuroscience Letters, pp. 81-85, 570, 2014.

[26] Y. H. Min, H. Khaza, M. Sokhini, A. Mutalib, and I. Musa, “The comparative effects between tocotrieonol-rich fraction (TRF) and $\alpha$-tocopherol on glutamate toxicity in neuron-astrocyte mono- and co-culture systems," International Journal of Biomedical and Advance Research, vol. 4, no. 6, pp. 403-409, 2013. 


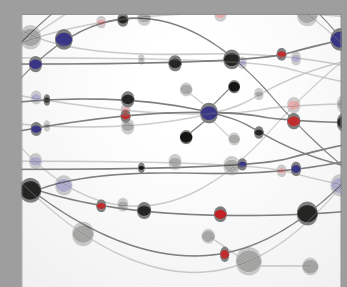

The Scientific World Journal
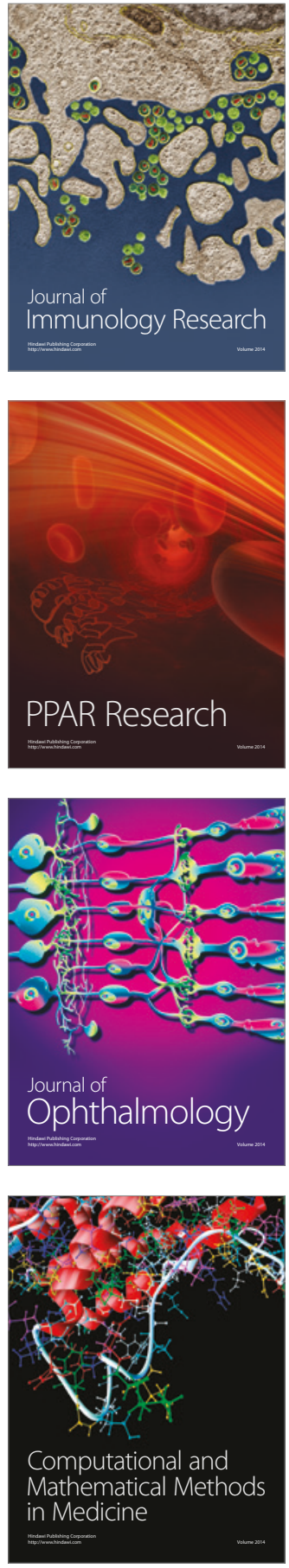

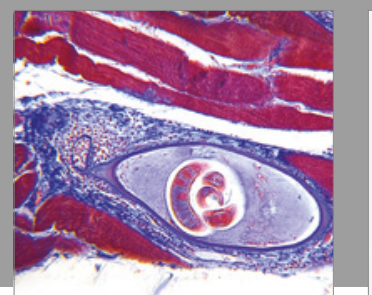

Gastroenterology Research and Practice
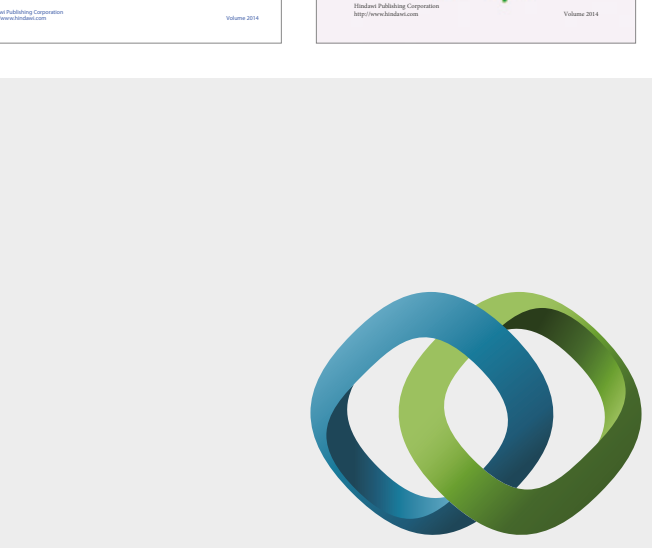

\section{Hindawi}

Submit your manuscripts at

https://www.hindawi.com
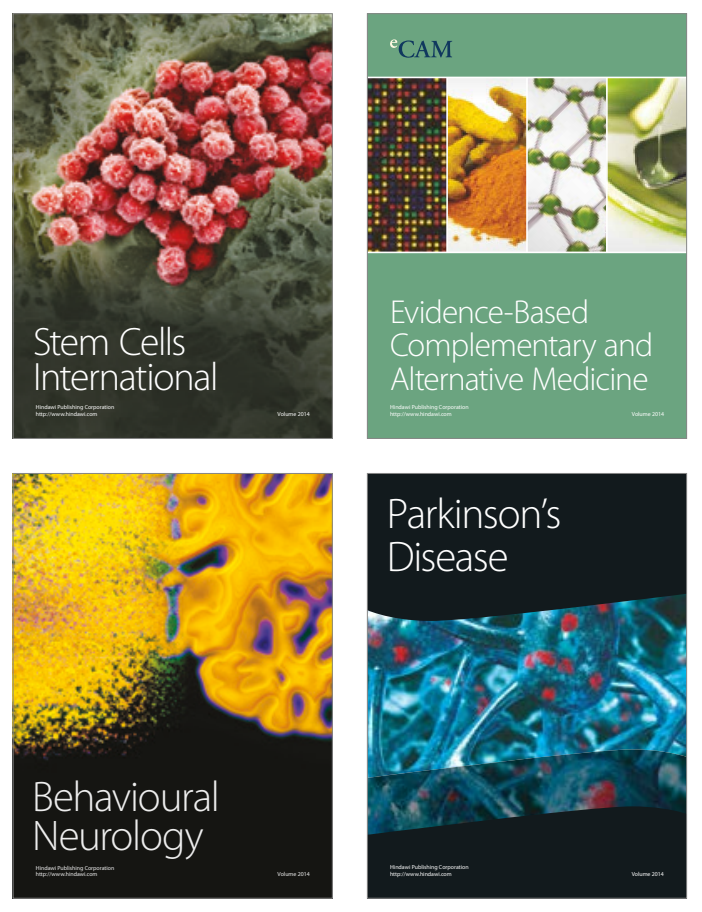
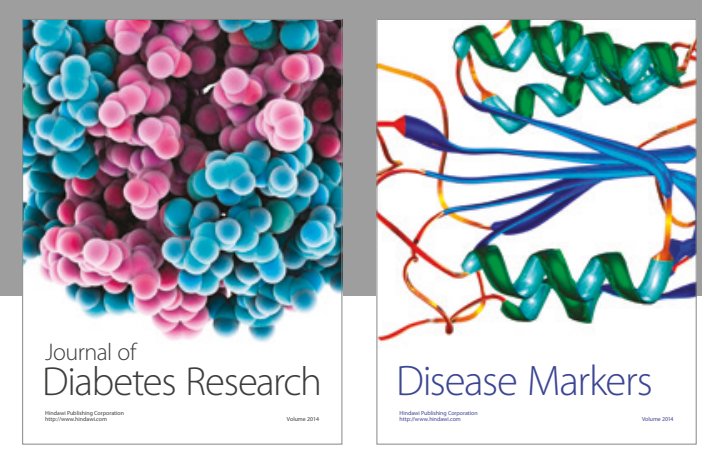

Disease Markers
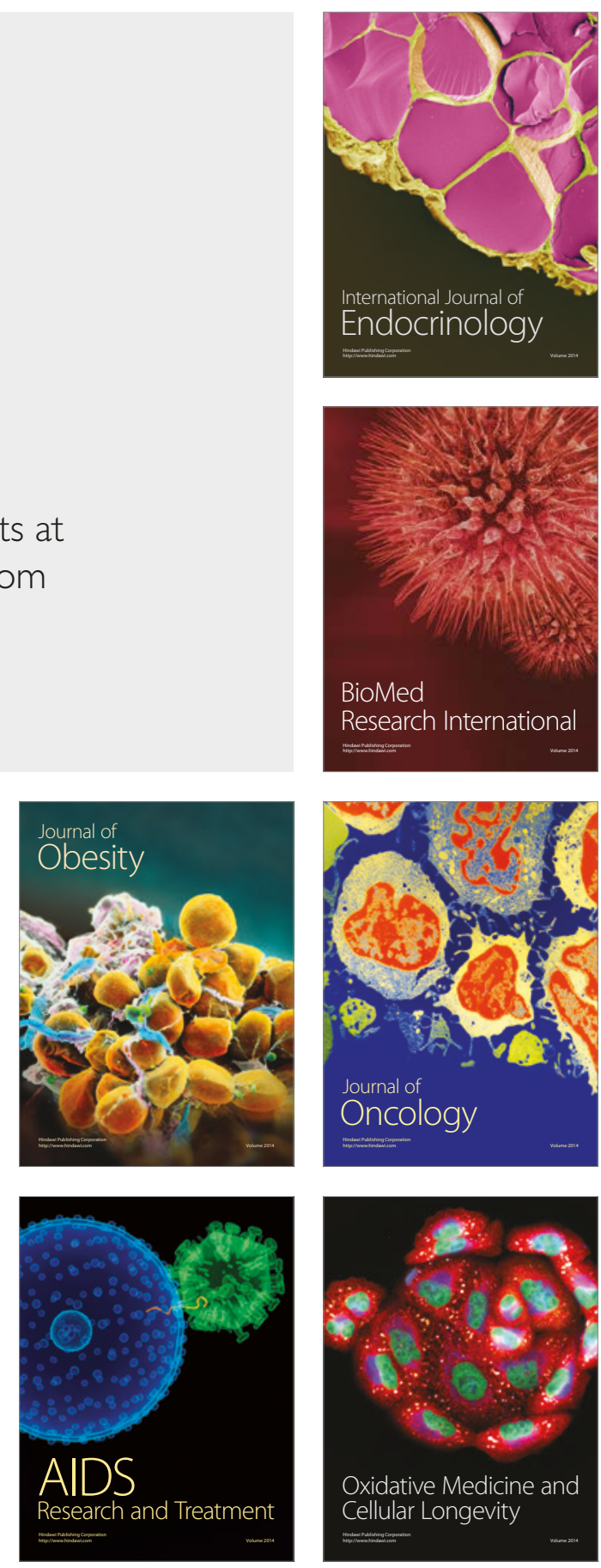